\title{
RESPOSTA DO ABACAXIZEIRO À ADIÇÃO DE NITROGÊNIO, POTÁSSIO E CALCÁRIO EM LATOSSOLO AMARELO DO NORDESTE PARAENSE ${ }^{1}$
}

\author{
CARLOS ALBERTO COSTA VELOSO ${ }^{2}$; ANTONIO HENRIQUE LOPES OEIRAS ${ }^{3}$; \\ EDUARDO JORGE MAKLOUF CARVALHO ${ }^{4}$; FRANCISCO R. SARMANHO DE SOUZA ${ }^{5}$
}

\begin{abstract}
RESUMO - O presente trabalho foi desenvolvido no período compreendido entre abril de 1997 e novembro de 1998, com o objetivo de avaliar o efeito da aplicação do nitrogênio e do potássio em diferentes níveis de calagem sobre a produtividade e qualidade do fruto do abacaxizeiro, num Latossolo Amarelo distrófico (Oxisol), no município de Capitão Poço, localizado na mesorregião do nordeste paraense. Os tratamentos constaram de quatro doses de nitrogênio $(0 ; 6 ; 12 \mathrm{e} 18 \mathrm{~g} / \mathrm{planta}$ de $\mathrm{N})$ na forma de uréia; quatro doses de potássio $\left(0 ; 9 ; 18\right.$ e $27 \mathrm{~g}$ /planta de $\left.\mathrm{K}_{2} \mathrm{O}\right)$ na forma de cloreto de potássio e duas doses de calcário dolomítico ( 0 e 1 t/ha). Utilizou-se o delineamento em blocos ao acaso, com três repetições, sendo os tratamentos dispostos em esquema de parcelas subdivididas, 4 x 4 x 2, correspondendo a quatro doses de nitrogênio, quatro doses de potássio e duas doses de calcário. Na parcela, ficaram as doses de calcário e, na subparcela, as combinações das doses de nitrogênio e potássio. Cada subparcela foi composta de 60 plantas, com 32 plantas úteis da cultivar "Pérola", espaçadas $90 \mathrm{~cm}$ entre fileiras duplas, $40 \mathrm{~cm}$ entre as filas simples e $30 \mathrm{~cm}$ entre plantas. A calagem não aumentou a produção e o teor de $\mathrm{K}$ nas folhas. Além disso, diminuiu o tamanho dos frutos. A adubação nitrogenada não teve efeito na produção e peso do fruto com coroa; na presença das doses de potássio, elevou o rendimento de suco do abacaxi. A adição de potássio, na forma de cloreto de potássio, aumentou a produção com a dose de $22 \mathrm{~g}$ /planta de $\mathrm{K}_{2} \mathrm{O}$, sendo que foi obtida a produção máxima de $79 \mathrm{t} / \mathrm{ha}$ de frutos com coroa. O diâmetro e comprimento do fruto aumentaram com as doses de potássio, e a acidez do fruto decresceu linearmente. Os teores de $\mathrm{Ca}, \mathrm{Mg}, \mathrm{N}$ e $\mathrm{K}$ nas folhas aumentaram com a aplicação de calcário e de adubos nitrogenados e potássicos.
\end{abstract}

Termos para indexação: Ananas comosus, adubação, nutrição mineral, calagem e qualidade de fruto.

\section{RESPONSE OF PINEAPPLE TO NITROGEN, POTASSIUM AND LIMESTONE IN A YELLOW LATOSOL IN BRAZIL}

\begin{abstract}
This work was carried out between April 1997 and November 1998, with the objective of evaluating the effect of the nitrogen and potassium rates and liming levels on pineapple yield and fruit quality. The treatments consisted of four levels of nitrogen $(0 ; 6 ; 12$ and $18 \mathrm{~g} / \mathrm{plant}$ of $\mathrm{N})$ in the urea form; four potassium levels $\left(0 ; 9 ; 18\right.$ and $27 \mathrm{~g} / \mathrm{plant}$ of $\left.\mathrm{K}_{2} \mathrm{O}\right)$ in the form of potassium chloride and two levels of dolomite lime ( 0 and $1 \mathrm{t} / \mathrm{ha}$ ). The experimental design was randomized blocks with three replications, being the treatments arranged in split plots $(4 \times 4 \times 2$, corresponding to four doses of nitrogen, four potassium levels and two levels of lime). In the plots lime levels were applied and in the subplots combinations of the levels of nitrogen and potassium were applied. Each subplot was composed of 60 plants of cultivar "Pérola", with 32 plants used for sampling ", spaced $90 \mathrm{~cm}$ in double arrays, $40 \mathrm{~cm}$ between the simple lines and $30 \mathrm{~cm}$ between plants in the same line. It was verified that liming didn't influence pineapple production, but it produced a better use of the potassium, with the addition of calcium and magnesium in the soil. The application of urea did not have any effect on the fruit production and weight, in the presence of potassium levels it elevated the yield of the pineapple juice. The potassium addition in the form of potassium chloride increased the production with the level of $22 \mathrm{~g} / \mathrm{plant}$ of $\mathrm{K}_{2} \mathrm{O}$, being expected a maximum production of $79 \mathrm{t} / \mathrm{ha}$ of fruits with crown. The diameter and length of the fruit increased with the potassium levels and the acidity of the fruit decreased lineally. The levels of $\mathrm{Ca}, \mathrm{Mg}, \mathrm{N}$ and $\mathrm{K}$, in the leaves increased with application of the lime of the nitrogen and potash fertilizers.
\end{abstract}

Index terms: Ananas comosus, fertilization, mineral nutrition, liming and fruit quality.

\section{INTRODUÇ̃̃o}

O Brasil é um dos três maiores produtores mundiais de abacaxi, sendo o maior produtor na América do Sul. Entre os principais Estados produtores, estão Minas Gerais, Pará e Paraíba (IBGE, 1997).
No Estado do Pará, a cultura do abacaxi tem sido importante para a economia de alguns municípios, por ser uma espécie rústica e adaptada às condições edafoclimáticas adversas que ocorrem nessa região. Na Ilha de Marajó, existem áreas planas extensas com mais de 30 anos de tradição no cultivo do abacaxizeiro. Os municípios de maior produção são Cachoeira

1 Trabalho $\mathrm{n}^{\circ}$ 198/99. Recebido: 27/12/1999. Aceito para publicação: 05/05/2001.

2 Eng $^{\circ}$ Agr $^{\circ}$, Dr. Embrapa Amazônia Oriental, Caixa Postal 48, CEP 66.095-100. Belém, PA.

$3 \mathrm{Eng}^{\mathrm{o}} \mathrm{Agr}^{\mathrm{0}}$, CITROPAR, Km 8 do ramal Arauari, Rod. PA 253, CEP 68650-000. Capitão Poço, PA.

4 Eng $^{\circ}$ Agr $^{\circ}$. Dr., Prof ${ }^{\mathrm{a}}$ Titular. Escola Superior de Agricultura de Lavras - Departamento de Ciência do Solo. ESAL/LAVRAS, Caixa Postal 37 , CEP 37200-000. Lavras, MG.

5 Eng $^{\circ}$ Agr $^{\circ}$, MSc., Embrapa Amazônia Oriental, Caixa Postal 48, CEP 66.095-100. Belém, PA. 
do Arari e Salvaterra, sendo os municípios de Soure e Ponta de Pedras com tendência de expansão. No sul do Pará, destacam-se os municípios de Floresta, Conceição do Araguaia e Redenção (Rodrigues \& Alves, 1998).

Segundo Netto et al. (1996), a participação do Brasil no mercado externo dessa fruteira é pequena apesar de ser típico das regiões tropicais e subtropicais, e altamente consumido em todo o mundo, tanto in natura quanto na forma de produtos industrializados. No entanto, segundo os autores, para se ter competitividade no mercado externo, é necessária a oferta de frutos de excelente qualidade.

Uma adubação equilibrada propicia maiores produções, obtenção de frutos de melhor qualidade e maior resistência a pragas e doenças (Malavolta, 1980).

Os solos do Estado do Pará, em sua grande maioria, apresentam baixa fertilidade natural e baixa saturação por bases. Segundo Paula et al. (1998), os nutrientes mais exigidos pelo abacaxizeiro são potássio, nitrogênio e cálcio. Também Paula et al. (1991) observaram em um experimento sobre calagem e adubação do abacaxizeiro com nitrogênio e potássio, em um Latossolo Vermelho de Minas Gerais, que a calagem não promoveu aumentos na produção, mas propiciou melhor utilização do potássio pelas plantas. A adubação potássica promoveu aumentos na produção nas doses de 720 e $936 \mathrm{~kg} / \mathrm{ha}$ de $\mathrm{K}_{2} \mathrm{O}$, respectivamente, na presença e ausência de calagem. $\mathrm{Na}$ presença de $\mathrm{N}$ e $\mathrm{K}$, a produção máxima foi de $34 \mathrm{t} / \mathrm{ha}$.

Desse modo, o objetivo deste trabalho foi avaliar o efeito da aplicação do nitrogênio e do potássio sob a presença e ausência de calagem para o cultivo do abacaxizeiro na mesorregião do nordeste paraense.

\section{MATERIAL E MÉTODOS}

$\mathrm{O}$ experimento foi conduzido na área da fazenda da CITROPAR - Cítricos do Pará S.A., situada na mesorregião do nordeste paraense, município de Capitão Poço, no período compreendido entre abril de 1997 e novembro de 1998, em solo classificado como Latossolo Amarelo distrófico, textura francoarenosa (Oxisol), cuja amostragem, anterior à instalação do experimento, foi efetuada na camada de $0-20 \mathrm{~cm} \mathrm{de}$ profundidade, para a caracterização química e física (Tabela 1). O clima do município é do tipo Ami (Köppen), com precipitação de $2.502 \mathrm{~mm}$ anual, com freqüência média de 140 a 180 dias de chuvas, ocorrendo um período de maior precipitação nos meses de fevereiro março e abril, temperatura média anual de $26,9^{\circ} \mathrm{C}$ e umidade relativa média de $80 \%$ (Bastos, 1972).

Utilizou-se o delineamento em blocos ao acaso, com três repetições, sendo os tratamentos dispostos em esquema de parcelas subdivididas, correspondendo a quatro doses de nitrogênio, quatro de potássio e duas de calcário. Na parcela, ficaram as doses de calcário e, na subparcela, as combinações das doses de nitrogênio e potássio.

Foi plantada a cultivar Pérola (Ananas comosus L. Merril), com mudas tipo rebentos de peso médio em torno de 180 gramas, com espaçamento de $90 \mathrm{~cm}$ entre fileiras duplas, $40 \mathrm{~cm}$ entre as filas simples e $30 \mathrm{~cm}$ entre plantas. Cada subparcela foi composta de 60 plantas, com 32 plantas úteis.

Os tratamentos corresponderam a quatro doses de nitrogênio $(0 ; 6 ; 12$ e $18 \mathrm{~g} /$ planta de $\mathrm{N})$ na forma de uréia; e quatro doses de potássio $\left(0 ; 9 ; 18\right.$ e $27 \mathrm{~g} /$ planta de $\left.\mathrm{K}_{2} \mathrm{O}\right)$ na forma de cloreto de potássio. A necessidade de calagem foi baseada na elevação da saturação por bases de acordo com Raij (1983), sendo que a calagem foi realizada com 40 dias de antecedência do plantio, nas doses de 0 e $1 \mathrm{t} / \mathrm{ha}$ de calcário dolomítico com PRNT 90\%. A adubação fosfatada foi realizada de uma única vez na cova de plantio, com $3 \mathrm{~g} /$ planta de $\mathrm{P}_{2} \mathrm{O}_{5}$, na forma de superfosfato simples. A adubação nitrogenada e potássica foi parcelada em quatro vezes, com intervalos de 60 dias, em cobertura, no $3^{\circ}, 5^{\circ}, 7^{\circ}$ e $9^{\circ}$ mês, após o plantio.

A indução floral foi feita aos doze meses de idade, aplicando-se, na roseta central, $50 \mathrm{ml} /$ planta da solução de Ethrel. A amostragem de folhas foi efetuada aos dezoito meses de idade, segundo Manica et al. (1984). Coletaram-se quatro folhas por planta, uma em cada quadrante, num ângulo de $45^{\circ}$, retirando-se a porção basal não clorofilada para análise.

As amostras de folha foram colocadas para secar em estufa com circulação forçada de ar, temperatura entre 60 e 65 ${ }^{\circ} \mathrm{C}$, por cerca de quatro dias. Depois de seco, o material foi moído em moinho tipo Willey com peneira de 20 malhas e acondicionado em saquinhos de papel para análises dos teores totais de $\mathrm{N}, \mathrm{P}, \mathrm{K}, \mathrm{Ca}, \mathrm{Mg}, \mathrm{S}, \mathrm{B}, \mathrm{Cu}, \mathrm{Mn}$ e $\mathrm{Zn}$, seguindo-se os métodos descritos por Malavolta et al. (1989).

Os frutos das plantas úteis foram contados, pesados e feita análise qualitativa em amostra de cada planta útil da parcela, para a determinação do peso médio, produção $(\mathrm{t} / \mathrm{ha})$, diâmetro do fruto, comprimento do fruto, teor de suco, acidez total titulável, sólidos solúveis totais e relação sólidos solúveis totais/acidez total.

Os dados obtidos foram submetidos à análise estatística, utilizando-se do programa estatístico SAS (Statistical Analysis System), utilizando-se dos módulos GLM, ANOVA E REG. Foram ajustadas equações de regressão, para todas as variáveis estudadas, em função das doses de $\mathrm{N} \mathrm{e}_{2} \mathrm{O}$. Efetuouse análise de correlação linear entre as variáveis massa média de frutos, produção de frutos ( $\mathrm{t} / \mathrm{ha}$ ), diâmetro do fruto, comprimento do fruto, teor de suco, acidez total titulável, sólidos solúveis totais e relação sólidos solúveis /acidez.

\section{RESULTADOS E DISCUSSÃO}

\section{Produção e peso dos frutos}

Pela análise de correlação linear, detectou-se uma associação positiva e significativa entre a produção de frutos, diâmetro de frutos e comprimento de frutos. Não houve correlação significativa entre produção de frutos com massa média dos frutos, conforme Tabela 2. Entretanto, a análise de variância não indicou efeito significativo da calagem sobre a produção do abacaxi, o que coincide com os dados obtidos por Magalhães et al. (1978), demonstrando, mais uma vez, que o abacaxizeiro tem boa tolerância à acidez do solo. Houve efeito significativo da aplicação de potássio, sendo que a produção máxima de $79 \mathrm{t} \mathrm{ha}^{-1}$ de frutos com coroa foi obtida com a dose de $22 \mathrm{~g} /$ planta de $\mathrm{K}_{2} \mathrm{O}$ (Figura 1a). Isto evidencia a exigência alta ao potássio pela cultura do abacaxi. Segundo Malavolta (1980), quando o nível de cálcio no solo é baixo, adições de cálcio irão aumentar a absorção de potássio, pois o cálcio regula 
a estrutura e funcionamento das membranas.

Para a massa média dos frutos, ocorreu efeito significativo das doses de potássio e da interação calagem x doses de potássio. Respostas a essa interação também foram encontradas por Paula et al. (1991). O desdobramento para potássio dentro dos níveis de calagem é apresentado na Figura $1 b$, onde se observa que a massa média dos frutos na ausência da calagem foi superior em relação à presença da calagem. Conforme relato de Malavolta (1982), em solos com baixa saturação em cálcio e magnésio, o potássio fornecido pelo fertilizante pode ocupar os sítios disponíveis para a troca de cátions em lugar de ficar na solução do solo, onde seria absorvido pela raiz.

\section{Diâmetro e comprimento do fruto}

A análise de variância revelou efeito significativo para potássio sobre o diâmetro do fruto. Para o comprimento dos frutos, a análise de variância indicou efeito significativo para potássio e interação nitrogênio x calagem.

$\mathrm{O}$ efeito de doses de potássio sobre o diâmetro dos frutos é de forma quadrática, com ponto máximo em 19,7 g de $\mathrm{K}_{2} \mathrm{O}$ /planta, correspondente ao diâmetro do fruto estimado de 40,5 cm (Figura 2). Bezerra et al.(1981) obtiveram maior diâmetro do fruto de abacaxi com uso de maiores doses de potássio. Os autores observaram efeito significativo da interação entre as doses de nitrogênio e doses de potássio, favorecendo o desenvolvimento do fruto de abacaxi.

O comprimento dos frutos foi influenciado por doses de nitrogênio, na ausência e na presença da calagem, de forma quadrática, com pontos máximos de 9,4 e 11,4 g de N/planta, correspondente ao comprimento dos frutos, estimado em 22,0 e $21,8 \mathrm{~cm}$, respectivamente, nos tratamentos sem e com calagem (Figura 3a). A relação entre a aplicação de $\mathrm{K}$ e o comprimento dos frutos também possui representação quadrática, com ponto máximo em 22,7 g de $\mathrm{K}_{2} \mathrm{O}$ /planta (comprimento do fruto estimado: 22,2 cm) (Figura 3b). Bezerra et al.(1981) observaram efeito significativo para $\mathrm{N}$ e $\mathrm{K}$, e a interação entre as doses de nitrogênio e doses de potássio favorecendo o comprimento do fruto de abacaxi.

\section{Concentração de nutrientes nas folhas}

Os teores de N, P, K, Ca, Mg, S, B, Cu, Mn e Zn no tecido foliar do abacaxizeiro "Pérola", em função das doses de nitrogênio, potássio e calcário, encontram-se na Tabela 3. Verifica-se que houve elevação nos teores foliares de $\mathrm{N}$ e K com a aplicação da uréia e do cloreto de potássio e de $\mathrm{Ca}$ e $\mathrm{Mg}$ com a realização da calagem.

Os teores de nitrogênio, encontrados no tecido foliar, revelaram que a adubação nitrogenada foi adequada, encontrando-se dentro da faixa adequada de nutrição do abacaxizeiro, ou seja, a aplicação de $12 \mathrm{~g}$ de N/planta proporcionou teor foliar de 12,9 $\mathrm{g} \mathrm{kg}^{-1}$ de $\mathrm{N}$ (Haag et al., 1963).

A adubação potássica proporcionou comportamento semelhante do abacaxizeiro com as doses estudadas, em que, com a aplicação de $18 \mathrm{~g}$ de $\mathrm{K}_{2} \mathrm{O}$ /planta, obteve-se teor foliar de $17,3 \mathrm{~g} \mathrm{~kg}^{-1}$ de $\mathrm{K}$, considerado adequado por Hiroce et al.(1977).

A calagem aumentou os teores de $\mathrm{Ca}$ e $\mathrm{Mg}$ trocáveis no solo, o que contribui para o acréscimo no tecido foliar do abacaxizeiro. Com a aplicação de $1 \mathrm{t} \mathrm{ha}^{-1}$ de calcário dolomítico, obtiveram-se teores foliares de $11,2 \mathrm{~g} \mathrm{~kg}^{-1}$ de Ca e 2,6 $\mathrm{g} \mathrm{kg}^{-1} \mathrm{de}$ $\mathrm{Mg}$, considerados abaixo da faixa nutricional adequada por Haag et al. (1963).

A adubação potássica reduziu os teores foliares de Ca e Mg (Tabela 3). De acordo com Malavolta (1982), quando o $\mathrm{K}$ é aplicado em uma cultura que responde a este nutriente, $\mathrm{o}$ teor de $\mathrm{Mg}$ no tecido foliar geralmente reduz-se a um nível abaixo do exigido para uma alta produção.

\section{Qualidade do fruto}

A análise de correlação linear mostrou relação negativa entre a produção e a acidez total, não detectando correlação significativa entre a produção de frutos e o teor de suco e sólidos solúveis (Tabela 2). A análise de variância revelou efeito significativo para as doses de nitrogênio e interação $\mathrm{N} \mathrm{x} \mathrm{K}$ sobre o rendimento de suco. Houve também efeito significativo das doses de $\mathrm{K}$ para o rendimento de suco, acidez total e a relação sólidos solúveis/acidez. A calagem e a interação calagem x N influíram significativamente na acidez e na relação sólidos solúveis/acidez. Fez-se o desdobramento para $\mathrm{N}$ dentro das doses de potássio, observando-se resposta quadrática para $\mathrm{N}$ dentro de K0, K1 e K3 (Figura 4a). Observou-se que, para os frutos de abacaxi atingirem um rendimento de suco máximo de $56,3 \%$ e $60,6 \%$, seria necessária a aplicação de 8,9 e 8,5 g/planta de N. Houve também resposta quadrática para potássio dentro de $\mathrm{N} 1$, N2 e N3 (Figura 4b). O rendimento estimado de 58,6\% e 60,5\%, do teor de suco de abacaxi, seria obtido com a aplicação de 17,5 e $12,3 \mathrm{~g} /$ planta de $\mathrm{K}_{2} \mathrm{O}$.

Os teores de sólidos solúveis totais dos frutos foram influenciados pela calagem e diminuíram com a aplicação de calcário; no entanto, a acidez dos frutos foi elevada significativamente com a adubação nitrogenada na presença da calagem, conforme mostra a Figura 5a. Na Figura 5b, observase que houve resposta linear decrescente das doses de potássio sobre a acidez do fruto.

TABELA 1 - Características químicas e físicas do solo da fazenda CITROPAR-III ${ }^{1}$

\begin{tabular}{cccccccccccc}
\hline $\begin{array}{c}\mathrm{pH} \\
\left(\mathrm{H}_{2} \mathrm{O}\right)\end{array}$ & $\mathrm{M} . \mathrm{O}$. & $\mathrm{P}$ & $\mathrm{Ca}$ & $\mathrm{Mg}$ & $\mathrm{K}$ & $\mathrm{Al}$ & $\mathrm{H}+\mathrm{Al}$ & $\begin{array}{c}\text { Areia } \\
\text { grossa }\end{array}$ & $\begin{array}{c}\text { Areia } \\
\text { fina }\end{array}$ & $\begin{array}{c}\text { Silte } \\
\text { Argila }\end{array}$ \\
& $\mathrm{g} \mathrm{kg} \mathrm{kg}^{-1}$ & $\mathrm{mg} \mathrm{kg}^{-1}$ & & & & & & & & \\
\hline 5,0 & 13,4 & 3,0 & 5,0 & 3,0 & 0,6 & 4,0 & 24,0 & 330,0 & 470,0 & 140,0 & 60,0 \\
\hline
\end{tabular}

1 Análises realizadas no Laboratório de Solos da Embrapa Amazônia Oriental. 
TABELA 2 - Matriz de correlação linear para produção de frutos(PROD), massa média de frutos (PMF), diâmetro de frutos (DIAMF), comprimento de frutos (COMPF), teor de suco (TS), sólidos solúveis totais (SST), acidez total (AT) e relação sólidos solúveis totais/acidez total (RSST/AT). Belém, PA. 1999.

\begin{tabular}{cccccccc}
\hline V ariáveis & PM F & D IAM F & COM PF & TS & S T & A T & R S S T A T \\
\hline P R O D & $0,2284 \mathrm{~ns}$ & $0,5104 * *$ & $0,5070 * *$ & $0,1969 \mathrm{~ns}$ & $0,1893 \mathrm{~ns}$ & $-0,2587 *$ & $0,3004 * *$ \\
P M F & ---- & $0,4869 * *$ & $0,4696 * *$ & $0,1751 \mathrm{~ns}$ & $0,1789 \mathrm{~ns}$ & $-0,3499 * *$ & $0,3925 * *$ \\
D IA M F & ---- & ----- & $0,7996 * *$ & $0,0918 \mathrm{~ns}$ & $-0,0889 \mathrm{~ns}$ & $-0,3135 * *$ & $0,2112 \mathrm{~ns}$ \\
C O M P F & ---- & ---- & ---- & $0,0506 \mathrm{~ns}$ & $-0,0387 \mathrm{~ns}$ & $-0,2806 *$ & $0,2314 \mathrm{~ns}$ \\
T S & ---- & ----- & ----- & ----- & $0,0905 \mathrm{~ns}$ & $-0,0788 \mathrm{~ns}$ & $0,0905 \mathrm{~ns}$ \\
S S T & ---- & ----- & ----- & ----- & ----- & $-0,2354 \mathrm{~ns}$ & $0,6426 * *$ \\
A T & ---- & ---- & ---- & ---- & ---- & ---- & $-0,8727 * *$ \\
\hline
\end{tabular}

* Significativo ao nível de 5\% de probabilidade

** Significativo ao nível de $1 \%$ de probabilidade

$\mathrm{NS}=$ Não significativo

TABELA 3 - Influência das doses de nitrogênio, potássio e calcário (t/ha) sobre os teores foliares de N, P, K, Ca, Mg, S, B, Cu, Mn e Zn em abacaxizeiro "Pérola".

\begin{tabular}{|c|c|c|c|c|c|c|c|c|c|c|}
\hline \multirow[t]{2}{*}{ Efeitos } & $\mathrm{N}$ & $\mathrm{P}$ & $\mathrm{K}$ & $\mathrm{Ca}$ & M g & $\mathrm{S}$ & $\mathrm{B}$ & $\mathrm{Cu}$ & $\mathrm{Mn}$ & $\mathrm{Zn}$ \\
\hline & \multicolumn{6}{|c|}{ - } & \multicolumn{4}{|c|}{ - - } \\
\hline \multicolumn{11}{|c|}{$\mathbf{N}$ g/planta } \\
\hline 0 & 10,3 & 2,0 & 2,7 & 7,7 & 5,2 & 1,1 & 18,4 & 4,1 & 403,2 & 16,2 \\
\hline 6 & 11,2 & 1,9 & 4,6 & 10,2 & 2,2 & 1,0 & 18,3 & 4,1 & 328,4 & 16,1 \\
\hline 12 & 12,9 & 2,1 & 6,6 & 7,9 & 2,4 & 0,8 & 20,1 & 4,1 & 442,8 & 14,3 \\
\hline 18 & 13,9 & 1,9 & 10,6 & 6,8 & 2,6 & 1,0 & 22,8 & 4,4 & 238,2 & 14,4 \\
\hline \multicolumn{11}{|l|}{$\underset{\mathrm{g} / \mathrm{planta}}{\mathbf{K}_{\mathbf{2}} \mathbf{O}}$} \\
\hline 0 & 12,9 & 1,9 & 4,7 & 7,5 & 2,6 & 1,1 & 18,4 & 4,1 & 406,2 & 16,2 \\
\hline 9 & 12,3 & 2,1 & 16,3 & 5,9 & 2,1 & 1,2 & 21,2 & 4,1 & 338,8 & 14,7 \\
\hline 18 & 13,6 & 1,8 & 17,4 & 5,8 & 1,8 & 1,2 & 18,3 & 4,7 & 425,4 & 16,7 \\
\hline 27 & 12,1 & 2,2 & 21,8 & 5,6 & 1,6 & 1,3 & 19,7 & 4,6 & 420,8 & 16,1 \\
\hline \multicolumn{11}{|l|}{$\begin{array}{c}\text { Calcário } \\
\text { t/ha }\end{array}$} \\
\hline 0 & 12,7 & 2,1 & 14,0 & 7,5 & 2,2 & 1,1 & 20,7 & 4,6 & 502,8 & 15,6 \\
\hline 1 & 12,9 & 2,1 & 14,1 & 11,2 & 2,6 & 1,2 & 21,3 & 5,0 & 357,2 & 14,8 \\
\hline
\end{tabular}



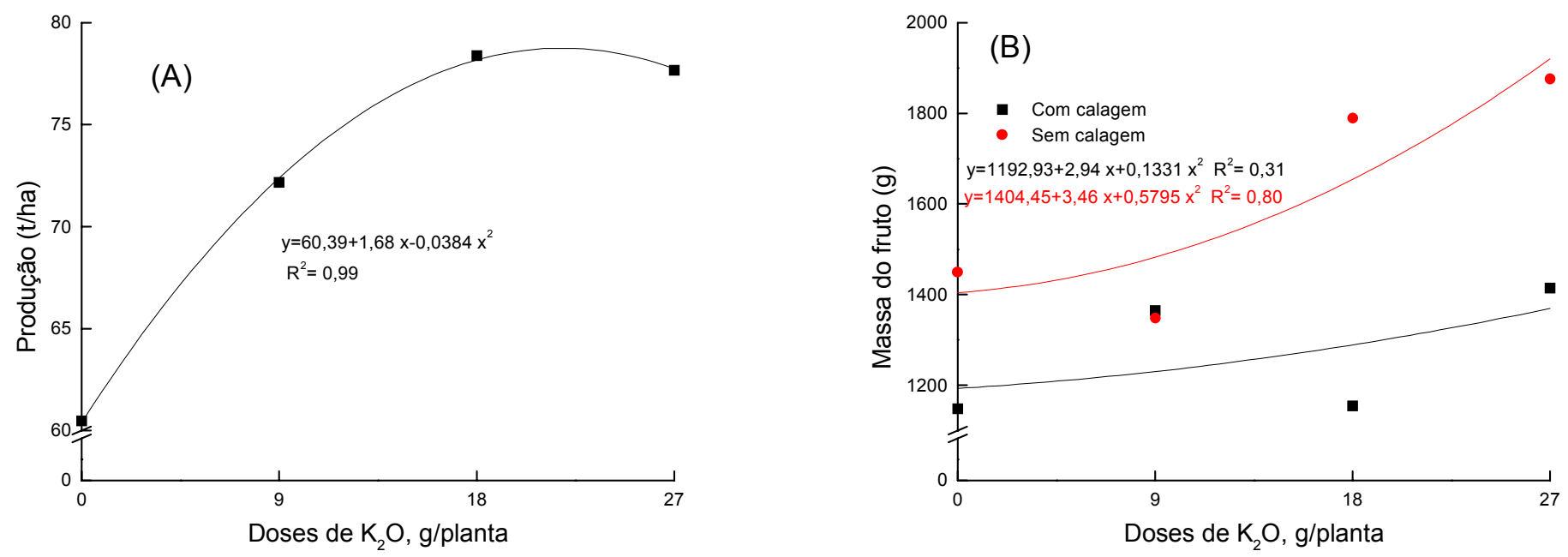

FIGURA 1 - Efeito das doses de potássio sobre a produção (a) e peso do fruto de abacaxi (b), na presença e na ausência da calagem.

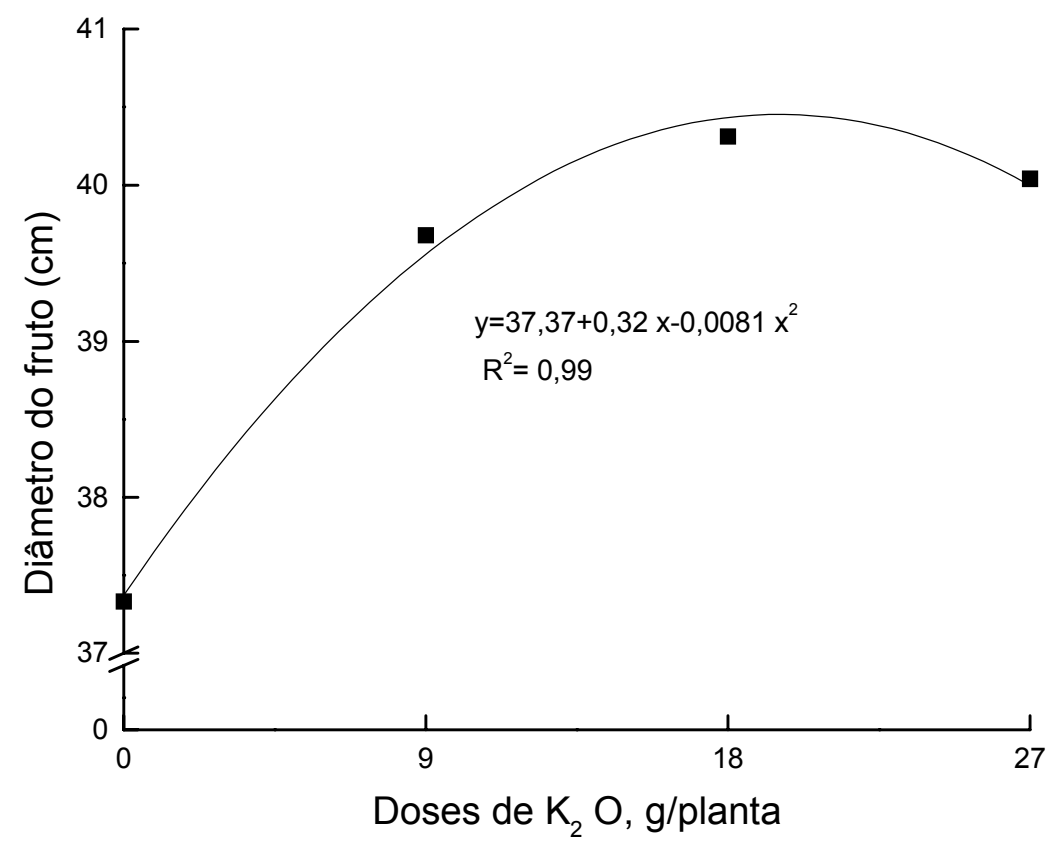

FIGURA 2 - Efeito das doses de potássio sobre o diâmetro do fruto de abacaxi "Pérola".
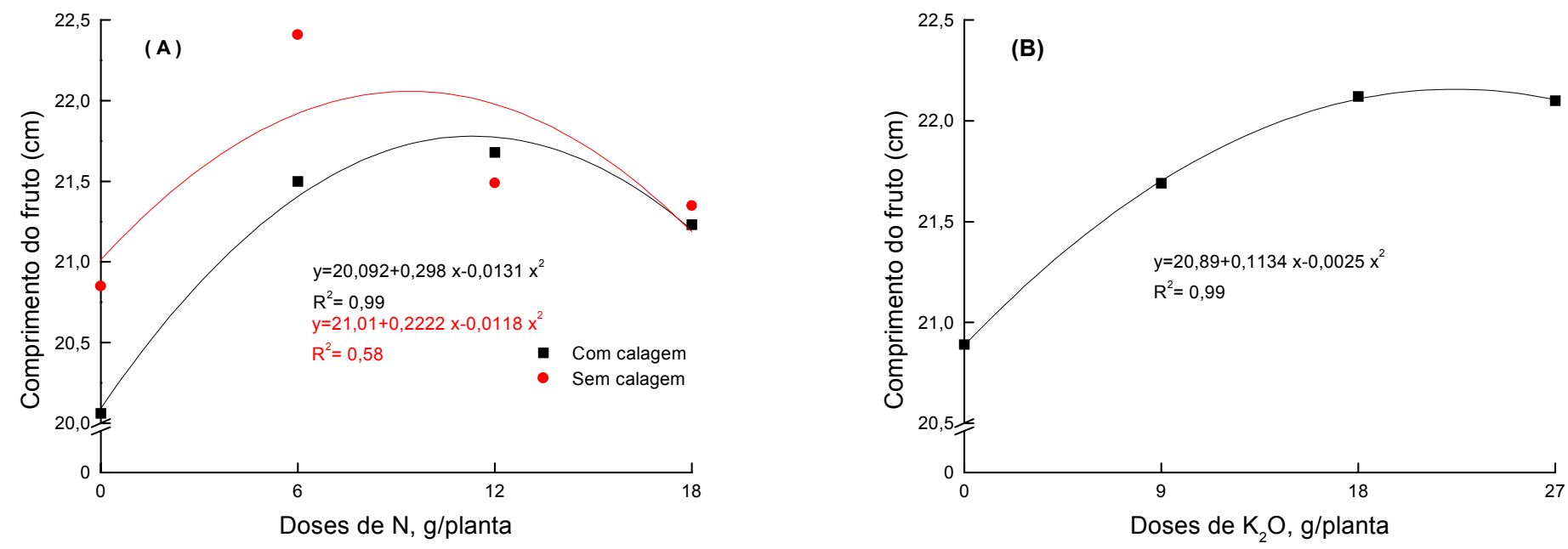

FIGURA 3 - Efeito das doses de nitrogênio na presença e na ausência da calagem (a) e das doses de potássio (b) sobre o comprimento do fruto de abacaxi "Pérola". Belém, PA, 1999. 

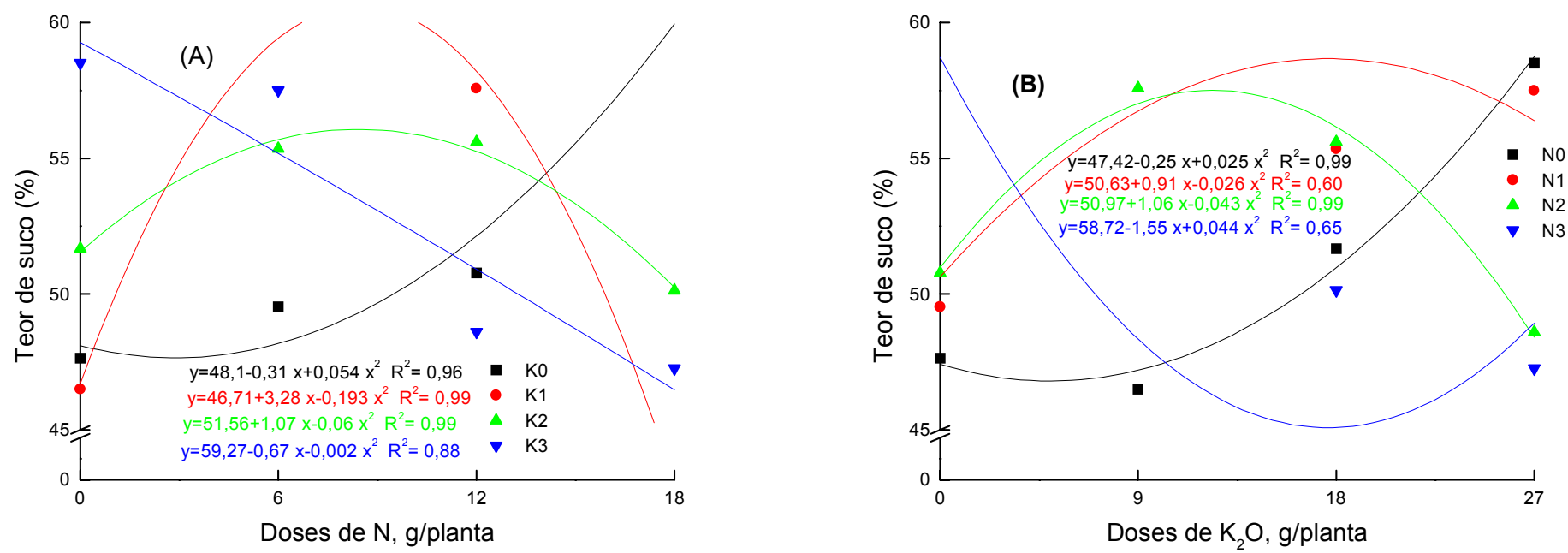

FIGURA 4 - Efeito das doses de nitrogênio na presença do K (a) e das doses de potássio na presença de N (b) sobre o teor de suco de abacaxi "Pérola". Belém, PA, 1999.
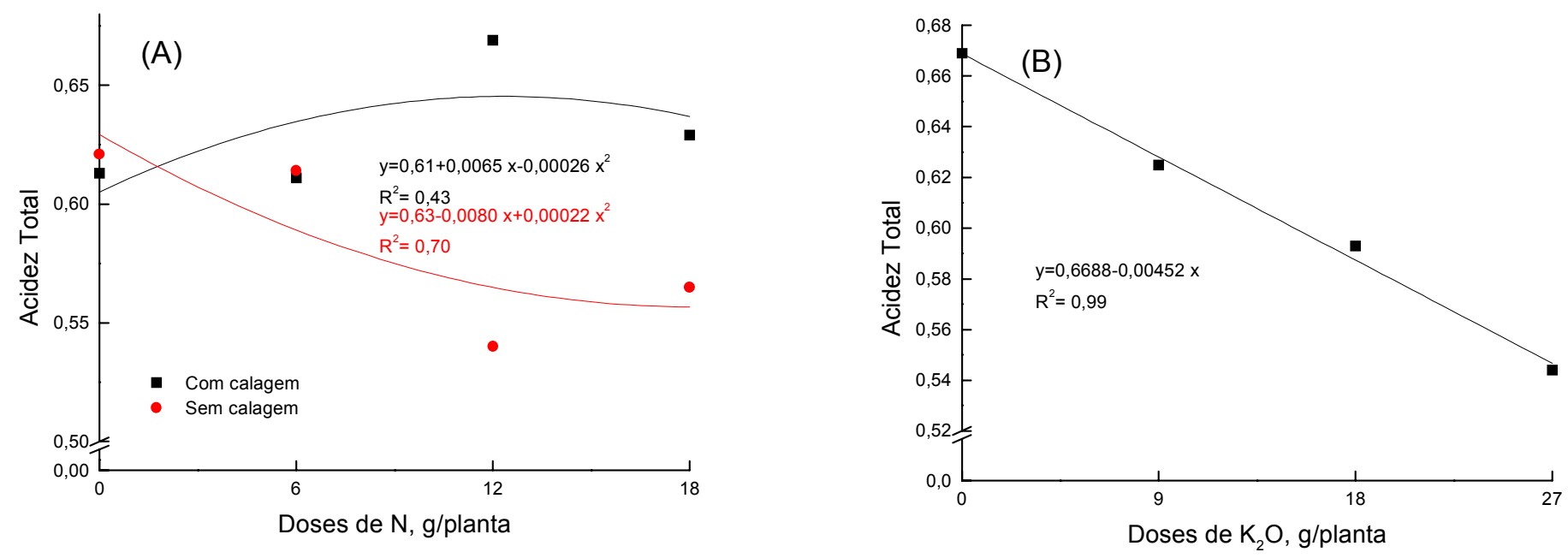

FIGURA 5 - Efeito das doses de nitrogênio na presença e na ausência da calagem (a) e das doses de potássio (b) sobre a acidez total do fruto de abacaxi "Pérola". Belém, PA, 1999.

\section{CONCLUSÕES}

1 - A calagem não aumentou a produção e o teor de K nas folhas. Além disso, diminuiu o tamanho dos frutos.

2 - A adubação nitrogenada não teve efeito na produção e massa do fruto com coroa, mas, na presença das doses de potássio, elevou o rendimento de suco do abacaxi.

3 - A adição de potássio, na forma de cloreto de potássio, aumentou a produção de forma quadrática, estimando-se uma produção máxima de $79 \mathrm{t} / \mathrm{ha}$ de frutos com coroa com a dose de $22 \mathrm{~g} /$ planta de $\mathrm{K}_{2} \mathrm{O}$. O diâmetro e o comprimento do fruto aumentaram com as doses de potássio, e a acidez do fruto decresceu linearmente.

4 - Os teores de $\mathrm{Ca}$ e $\mathrm{Mg}$, nas folhas, aumentaram com aplicação de calcário.

\section{REFERÊNCIAS BIBLIOGRÁFICAS}

ANUARIO ESTATÍSTICO DO BRASIL. Rio de Janeiro: IBGE,
1997. v.57, p.3-32.

BASTOS, T.X. O estado atual dos conhecimentos das condições climáticas da Amazônia brasileira. Belém: IPEAN, 1972. p.68-122. (Boletim Técnico, 54).

BEZERRA, J.E.F.; MAAZE, U.C.; SANTOS, V.F. dos; LEDERMAN, I.E. Efeito da adubação nitrogenada, fosfatada e potássica na produção e qualidade do abacaxizeiro cv. Smooth Cayenne. Revista Brasileira de Fruticultura, Recife, v.3, p.1$5,1981$.

HAAG, H.P.; ARZOLLA, S.; MELLO, F.A.F.; BRASIL SOBRINHO, M.O.C.; OLIVEIRA, E.R.; MALAVOLTA, E. Estudos sobre a alimentação mineral de abacaxi (Ananas sativus) Sch. Anais da Escola Superior de Agricultura "Luiz de Queiroz", Piracicaba, v.20, p33-40, 1963.

HIROCE, R.; BATAGLIA, O.C.; FURLANI, P.R.; FURLANI, A.M.C.; GIACOMELLI, E.J.; GALLO, J.R. Composição 
química inorgânica do abacaxizeiro (Ananas comosus Cayenne) da região de Bebedouro, SP. Ciência e Cultura, v.29, n.3, p.323326, 1977.

MAGALHÃES, A.F. de; SOUZA, L.F. da S.; CUNHA, G.A. P. da. Efeitos de N, P, K, S, micronutrientes e calagem em abacaxi Ananas comosus (L.)Merr. In: CONGRESSO BRASILEIRO DE FRUTICULTURA, 4., 1977, Salvador. Anais... Cruz das Almas: Sociedade Brasileira de Fruticultura, 1978. p.1-9.

MALAVOLTA, E. Elementos de nutrição mineral de plantas. São Paulo. Ceres, 1980. 251p.

MALAVOLTA, E. O potássio e a planta. 4. ed. Instituto da Potassa, 1982. 60p. (Boletim Técnico, 1).

MALAVOLTA, E.; VITTI, G.C.; OLIVEIRA, S.A . Avaliação do estado nutricional das plantas: princípios e aplicações. Piracicaba: POTAFOS, 1989. 201p.

MANICA, I.; PASSOS, L.P.; IUCHI, V.L.; DEFELIPO, B.V.; LICHTENBERG, L.A.; CONDÉ, A.R. Efeito de três doses de cloreto e sulfato de potássio na concentração de macronutrientes nas folhas do abacaxizeiro (Ananas comosus (L.)Merril) cultivar Smooth Cayenne em Visconde do Rio Branco, MG, Brasil. In: CONGRESSO BRASILEIRO DE FRUTICULTURA, 7., 1984, Florianópolis. Anais... Florianópolis: Sociedade Brasileira de Fruticultura, 1984. v.1, p.105-114.
NETTO, A.G.; CARVAlHO, V.D. de; BOTREL, N.; BLEINROTH, E.W.; MATALLO, M.; GARCIA, A.E.; ARDITO, E.F.G.; GARCIA, E.E.R.; BORDIN, M.R. Abacaxi para exportação: procedimentos de colheita e pós-colheita. Brasília. EMBRAPA-SPI, 1996. 41p. (FRUPEX. Publicações Técnicas, 23).

PAULA, M.B. de; CARVALHO, V.D. de; NOGUEIRA, F.D.; SOUZA, L.F. da S. Efeito da calagem, potássio e nitrogênio na produção e qualidade do fruto do abacaxizeiro. Pesquisa Agropecuária Brasileira, Brasília, v.26, n.9, p.1337-1343, 1991.

PAULA, M.B. de; MESQUITA, H.A. de; NOGUEIRA, F.D. Nutrição e Adubação do Abacaxizeiro. Informe Agropecuário, Belo Horizonte, v.19, n.195, p.33-39, 1998.

RAIJ, B. van. Avaliação da fertilidade do solo. 2. ed. Piracicaba. Instituto da Potassa \& Fosfato, Instituto Internacional da Potassa, 1983. 142p.

RODRIGUES, J.E.L.F.; ALVES, R.N.B. Situação Atual e Perspectivas da Abacaxicultura no Estado do Pará. Informe Agropecuário, Belo Horizonte, v.19, n.195, p.79, 1998.

SARRUGE, J.R.; HAAG, H.P. Análise química em plantas. Piracicaba. ESALQ/USP, 1974. 56p. 